DISTRIBUTION STATEMENT A. Approved for public release; distribution is unlimited.

\title{
Waves and fetch in the Marginal Ice Zone
}

\author{
Jim Thomson \\ 1013 NE $40^{\text {th }}$ St, Seattle WA 98105 \\ phone: (206) 616-0858 fax: (206)616-5467 email: jthomson@apl.uw.edu
}

Award Number: N00014-12-1-0113

http://www.apl.washington.edu/MIZ

FY14 report (year 3 of 5)

\section{LONG-TERM GOALS}

The long-term goal is to improve prediction of the arctic Marginal Ice Zone (MIZ) by improving basic understanding of the interaction between waves, sea ice, and open water (i.e., fetch).

\section{OBJECTIVES}

The primary objective is to improve wave source/sink parameterizations by directly measuring the growth and dissipation of waves in the MIZ. The secondary objective is to develop a surface wave climatology of the arctic ocean and the relation to the seasonal MIZ.

\section{APPROACH}

The technical approach is to use Surface Wave Instrument Floats with Tracking (SWIFT) buoys to measure waves, winds, and turbulence at the air-sea-ice interface (Thomson, 2012). The SWIFT deployments were successfully completed during the summer of 2014. These seasonal SWIFT measurements are placed in context using mutliyear subsurface Acoustic Wave And Current (AWAC) moorings and regional WAVEWATCH3 model results.

\section{WORK COMPLETED}

A total of six SWIFT buoys were deployed in the Beaufort and Chuckchi Seas during the summer of 2014: three from the R/V Ukpik in July, one from the R/V Araon in August, and two from the USCGC Healy in Auguest. Of these six, two from the Ukpik were allowed drift freely across the region in an endurance mode for two months. The other deployments were shorter and focused on detailed measuremens of processes, including an opportunistic dataset collected from the R/V Ukpik with waves incident on brash ice.

The endurance SWIFTs drifted westward and spent most the later part of August measuring the waves incident to the large array deployed by other DRI members. Around September 1, one of the SWIFTs (\#10) drifted into the ice (as indicated by telemetry images from the onboard camera) and immediately measured a sharp reduction in the waves (Figure 1). This SWIFT also reported reduced turbulence, lower salinity, and lower temperatures (both air and water) once in the ice. The winds, however were similar, suggesting that much of the wind stress in the ice goes directly to the ice (not the water or the waves). 


\section{Report Documentation Page}

Form Approved

OMB No. 0704-0188

Public reporting burden for the collection of information is estimated to average 1 hour per response, including the time for reviewing instructions, searching existing data sources, gathering and maintaining the data needed, and completing and reviewing the collection of information. Send comments regarding this burden estimate or any other aspect of this collection of information,

including suggestions for reducing this burden, to Washington Headquarters Services, Directorate for Information Operations and Reports, 1215 Jefferson Davis Highway, Suite 1204, Arlington

VA 22202-4302. Respondents should be aware that notwithstanding any other provision of law, no person shall be subject to a penalty for failing to comply with a collection of information if it

does not display a currently valid OMB control number.

1. REPORT DATE

30 SEP 2014

4. TITLE AND SUBTITLE

Waves and Fetch in the Marginal Ice Zone

6. $\operatorname{AUTHOR}(\mathrm{S})$

7. PERFORMING ORGANIZATION NAME(S) AND ADDRESS(ES)

University of Washington,Applied Physics Laboratory,1013 NE 40th Street,Seattle,WA,98105

9. SPONSORING/MONITORING AGENCY NAME(S) AND ADDRESS(ES)

\section{DATES COVERED}

00-00-2014 to 00-00-2014

5a. CONTRACT NUMBER

5b. GRANT NUMBER

5c. PROGRAM ELEMENT NUMBER

5d. PROJECT NUMBER

5e. TASK NUMBER

5f. WORK UNIT NUMBER

8. PERFORMING ORGANIZATION REPORT NUMBER

10. SPONSOR/MONITOR'S ACRONYM(S)

11. SPONSOR/MONITOR'S REPORT $\operatorname{NUMBER}(\mathrm{S})$

12. DISTRIBUTION/AVAILABILITY STATEMENT

Approved for public release; distribution unlimited

13. SUPPLEMENTARY NOTES

14. ABSTRACT

15. SUBJECT TERMS

16. SECURITY CLASSIFICATION OF:

a. REPORT

unclassified b. ABSTRACT

unclassified c. THIS PAGE

unclassified
17. LIMITATION OF ABSTRACT

Same as

Report (SAR)
18. NUMBER 19a. NAME OF

OF PAGES RESPONSIBLE PERSON

4 


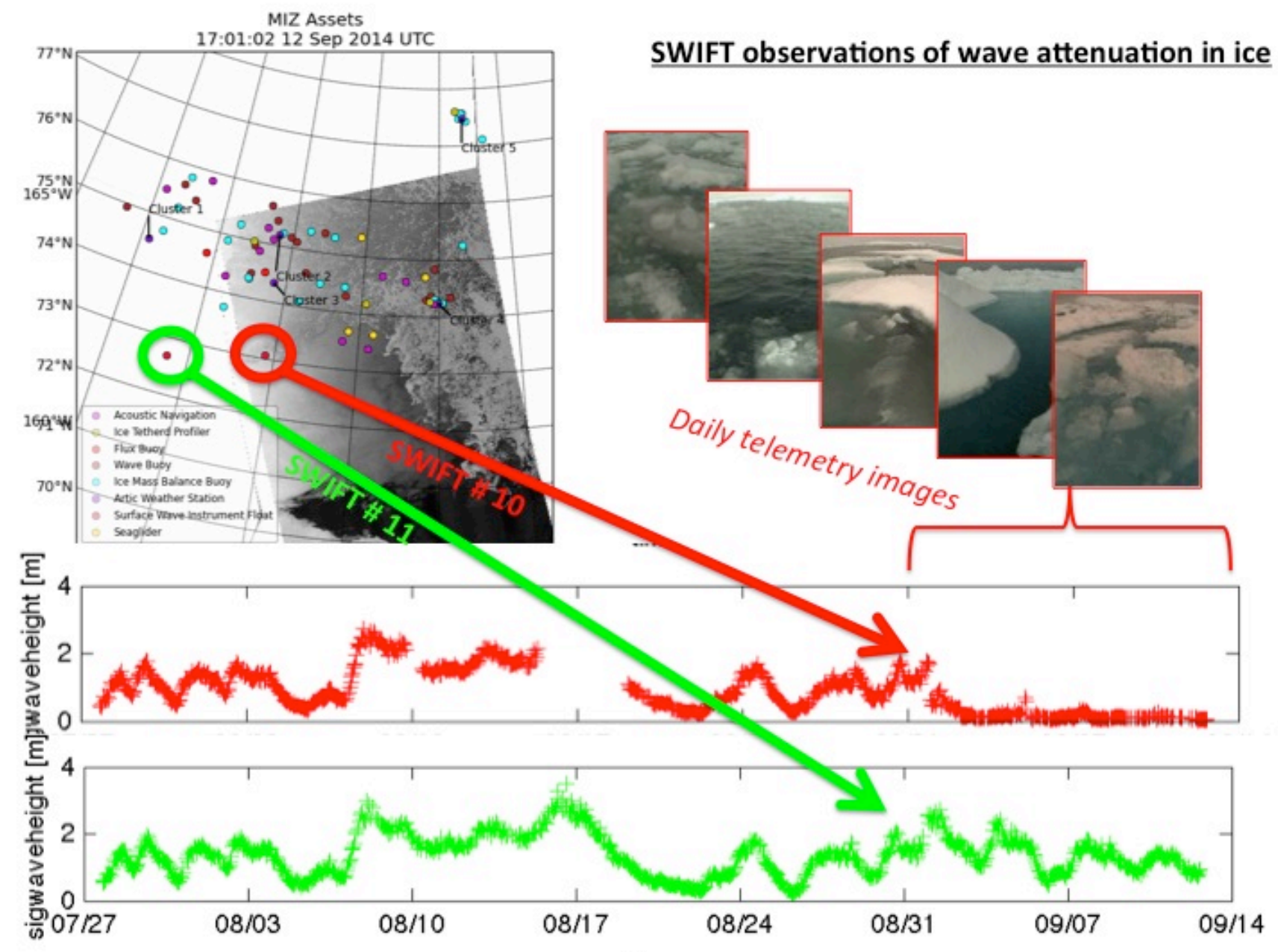

Figure 1. SWIFT wave height data from the endurance deployments during the 2014 MIZ experiment. SWIFT \#10 shows strong reduction of waves upon entering the ice around Sept 1 . The turbulence is similary reduced (not shown).

In addition, the first year-long time series from the AWAC on a Beaufort Gyre mooring 'A' was analyzed to determine the wave dependence on fetch. The instrument was redeployed on mooring ' $\mathrm{A}$ ' ( $\mathrm{N} 75, \mathrm{~W}$ 150), and another AWAC was added to mooring ' $\mathrm{D}$ ' (N 74, W 140). These instruments will be recovered, offloaded, and redeployed yearly through 2015 .

Data from the 2014 effort are posted and linked to the program website (apl.uw.edu/miz). Data processing is underway.

\section{RESULTS}

Data from the process measurements collected during the R/V Ukpik cruise show a clear link between waves, wind, turbulence, and ice. By placing a SWIFT offshore of the ice and then reseting it progressively farther into the ice, we measured a reduction in the high frequency tail of the wave spectrum via ice damping (Figure 2a). This high frequency tailed is termed the equilibrium range, and in open water it is directly related to the wind stress and the surface turbulence (Thomson et al, 2013). 
In the ice, this portion of the spectrum is reduced, even though the measured winds are the same. Likewise, the turbulence is reduced (Figure 2b). This implies that the effective stress on the waves and water is reduced in the ice, likely because a portion of the wind stress goes directly to the ice. This is confirmed by visual observation of very smooth water surface within the ice floes (i.e., damping short waves). This is consistent with existing models of frequency-dependent wave attentuation in ice, however it is the first known direct observation of the associated change in turbulence (and implied stress partitioning).
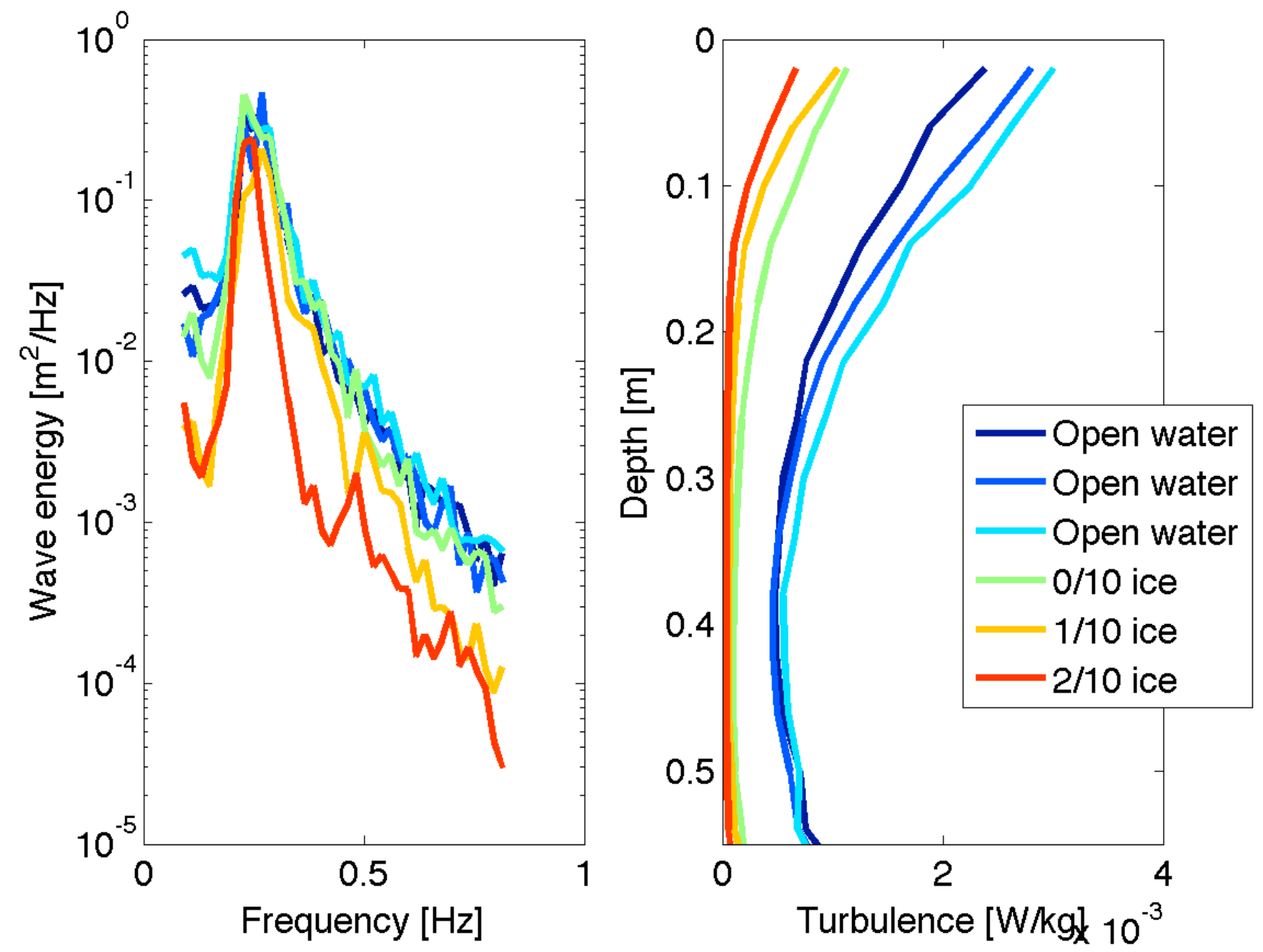

Figure 2. Wave energy frequency spectra and profiles of the turbulent dissipation rate measured by a SWIFT buoy at various ice concentrations (indicated by color).

In a complimentary effort, data analyzed from the AWAC mooring measurements, combined with ice maps from the National Ice Center (NIC), show a strong dependence of wave height on the open water distance (Figure 3). This is large scale effect of sea ice (as opposed to the local effects shown in Figure 2). 


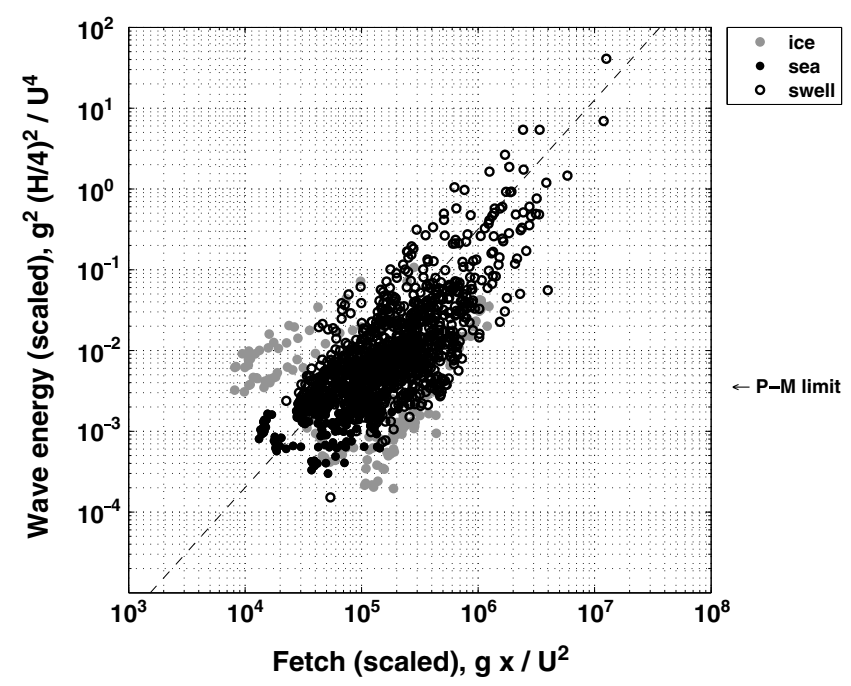

Figure 3. Wave energy, scaled by wind, versus open water fetch, also scaled by wind. Open water fetch is the strongest indicator of wave energy in the western Arctic Ocean.

\section{IMPACT/APPLICATIONS}

Improved wave and MIZ predictions in the Arctic Ocean will enable safe naval operations in the region.

\section{RELATED PROJECTS}

A completed contract with Scitor Corp. supported analysis of declassified satellite images for wave information in the Beaufort region.

Resources are data are shared with the "Sea State and Boundary Layer Physics of the Emerging Arctic Ocean" DRI. More information is at

http://www.apl.washington.edu/project/project.php?id=arctic_sea_state

\section{PUBLICATIONS}

Thomson, J. and E. Rogers, Swell and sea in the emerging Arctic Ocean, Geophys. Res. Lett., 41 (2014). [published, refereed].

Thomson, J., E. D’Asaro, M. Cronin, E. Rogers, R. Harcourt, and A. Shcherbina, Waves and the equilibrium range at Ocean Weather Station P, J. Geophys. Res., 118 (2013). [published, refereed].

Thomson, J. "Observations of wave breaking dissipation with SWIFT drifters," J. Atmos. and Ocean. Tech., 2012. [published, refereed].

Craig, L. et al, "Science Plan for the Mariginal Ice Zone program,” APL-UW Tech. Report 1201, 2012. [published]. 